\title{
Editorial
}

\section{Training Program in Gastroenterology: How Can It Survive the Pandemic?}

\author{
Catarina Brandão ${ }^{a}$ Ricardo Gorjão ${ }^{b, c}$

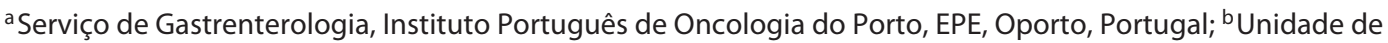 \\ Cirurgia Hepato-Bilio-Pancreática e de Transplantação, Centro Hospitalar Universitário de Lisboa Central, Lisbon, \\ Portugal; ' 'Serviço de Gastrenterologia, Hospital CUF Descobertas, Lisbon, Portugal
}

Keywords

COVID-19 · Training program · Gastroenterology

\section{Programa de Formação Específico em Gastrenterologia: Como Pode Sobreviver à Pandemia?}

\section{Palavras Chave}

COVID-19 · Formação específica · Gastrenterologia

The SARS-CoV-2 pandemic has brought radical changes to the regular practice of gastroenterology.

The transmission routes of the new coronavirus (droplets, aerosol and probably fecal-oral) put all gastroenterological activities at high risk of contamination, especially in the endoscopy digestive practice [1].

The exponential increase in COVID-19 cases in Europe led to the issuing of numerous recommendations by different national and international entities, which called for a profound reorganization of the gastroenterology departments [2-4]. The main focus was on clinical service prioritization, restrictive procedure triage and constrained settings of human and equipment resources.

\section{KARGER}

karger@karger.com www.karger.com/pjg
(C) 2020 Sociedade Portuguesa de Gastrenterologia Published by S. Karger AG, Basel

Karger

Open access

This article is licensed under the Creative Commons AttributionNonCommercial-NoDerivatives 4.0 International License (CC BYNC-ND) (http://www.karger.com/Services/OpenAccessLicense). Usage and distribution for commercial purposes as well as any distribution of modified material requires written permission.
Consequently, training programs and trainees were faced with unexpected challenges.

The specific training programs have undergone a remarkable evolution in an attempt to follow that of the specialties themselves, but none of them were prepared for a pandemic scenario.

Obviously, the impact on training programs is different according to the specialties and may even constitute a unique opportunity for some of them. In specialties such as public health, internal medicine, intensive care medicine or infectious diseases, trainees are being empowered with exceptional and incomparable knowledge, performance levels and skills.

Also for specialties not directly involved in the COVID-19 response, the reallocation of human resources constitutes an unquestionable training advantage, providing for the acquisition or consolidation of competences, impossible to program outside of an exceptional pandemic setting.

Even though health care personnel working in gastroenterology departments are not in the frontline, the impact on gastroenterology activity is still remarkable.

Online care and telephone consultations have been strongly suggested and should be provided, in order to minimize the presential clinical evaluations. The inpatient care approach is also changing. The entire hospital 
dynamic is undergoing a profound transformation, and even patients suffering from chronic illnesses with alarm symptoms/relapse resist seeking medical care. It was strongly suggested that gastrointestinal endoscopy units temporarily postponed elective, nonurgent activity and accurately identified time-sensitive procedures. Only essential and experienced endoscopy personnel should be present in the selected endoscopy cases (trainees are not allowed), and appropriate personal protective equipment (PPE) and infrastructures should be available.

All these aspects significantly weaken the structural pillars of gastroenterology training and bring trainees increased pressure due to the difficulty in achieving their training plan on time. Furthermore, dealing with psychological distress and infectious risks endangers the trainees' physical and mental health.

Additionally, the increasing pressure on health services has imposed the relocation of some gastroenterology interns to COVID-19 patient care, keeping them away from specialized clinical practice. Participation in postgraduate events and public scientific presentations, as required for the core curriculum, are also suspended for the time being.

In spite of the significant limitations such as diminished gastroenterology practice activity, the current situation might enhance scientific opportunities, allow for the acquisition of a wide range of theoretical knowledge and reinforce competences in the ability to adapt to a dynamic hospital reorganization, procedure eligibility and judicious use of PPE.

Trainees are health care professionals with inestimable value who ensure the continuity of medical care in the future and therefore must be protected. Their knowledge and abilities should also be taken into account, in order to improve the current situation.

The uncertainty about the future raises many doubts, and several issues deserve deep reflection and imminent decisions.

To minimize the negative impact of the pandemic, and in order to ensure that the training program remains feasible, even in necessarily atypical circumstances, there must be a connection between the different authorities in this matter.

In order to restrict presential events and to keep the focus on fighting the pandemic, the Portuguese authorities have postponed all final board exams and issued some guidelines for the reorganization of local training programs. The continuity of internships is guaranteed, provided that sufficient conditions for their completion are ensured.

While the continuity of internships connected with COVID-19 is easily approved, the access to more ad-

Gastroenterology Training in the COVID

Era vanced or differentiated practices is mostly suspended due to circulation restrictions and other measures imposed to control the pandemic.

The different agents involved in this process (trainees, trainers, training leaders and institutions) should take concerted efforts to reach an inclusive, individualized and timely planned decision.

The main goal must be to defend the intern's interests and to provide optimal conditions for the development of essential skills required for independent gastroenterology practice.

In the Portuguese gastroenterology training, the first year is dedicated to internal medicine and intensive care and therefore should not be affected by the current pandemic. In the second and third years, basic clinical and endoscopic gastroenterology skills should be achieved but eventual gaps can be filled in the remaining training time. The biggest challenge will be for the fourth- and fifth-year internships. Opportunities for optional training modules can be lost and not easily replaced. These unexpected circumstances must be overcome, and comprehensive measures should be considered.

A dynamic and timely supervision by the trainer is essential in order to promptly identify and overcome gaps in the individual training plan. A tremendous impact on training plans is already a reality but is also expected in the postpandemic gastroenterology activity, resulting from the increased pressure on clinical services to respond to the postponed and time-sensitive medical procedures. Efforts to reorganize training programs should not be limited to the outbreak period but include the postpandemic phase as well. The workload is inevitable, and it is essential that the trainees' activity remains focused on fulfilling their training requirements.

It is mandatory that trainees have the same opportunities regardless of local or regional circumstances. Furthermore, the gastroenterology training phases dictate a necessarily individual approach based on the year and specific stage.

The failure to achieve basic skills within the time schedule has to be addressed and may imply an extension of training time. Extraordinary assessment and recognition of competencies must be prepared to respond to this exceptional situation. The impossibility of completing advanced optional internships should be taken into account at the final exam evaluation, according to well-defined guidelines and protecting the intern. These optional internships are often the most desirable aims of trainees for which they have fought throughout their training route. This experience must be encouraged and promoted, even

GE Port J Gastroenterol 2020;27:224-226 
after the end of internship, to overcome frustrations and encourage personal and professional development.

The COVID-19 public health emergency continuously imposes changes on the gastroenterology exercise paradigm. Patients' and health care professionals' safety prioritization is consensual but is causing collateral damage. The gastroenterology training program is not an exception. Coherent, fair, context-adapted and feasible measures should be continuously implemented to minimize the most immediate impact and to prepare the reaction to future challenges that will not vanish and remain demanding.

\section{Disclosure Statement}

The authors have no conflicts of interest to declare.

\section{Author Contributions}

Both authors contributed equally to the editorial.
References
1 Repici A, Maselli R, Colombo M, Gabbiadini R, Spadaccini M, Anderloni A, et al. Coronavirus (COVID-19) outbreak: what the department of endoscopy should know. Gastrointest Endosc. 2020 Mar;pii:S0016-5107(20) 30245-5. Epub.

2 European Centre for Disease Prevention and Control. Download today's data on the geographic distribution of COVID-19 cases worldwide. Available from: https://www. ecdc.europa.eu/en/publications-data/downloadtodays-data-geographic-distribution-covid-19-cases-worldwide.
3 ESGE and ESGENA position statement on gastrointestinal endoscopy and the COVID-19 pandemic update 1 (18.03.2020). Available from: https://www.ESGE.com/publications/guidelines/.

4 Comunicado conjunto das Sociedades Portuguesas de Endoscopia Digestiva (SPED), Gastrenterologia (SPG) e Coloproctologia (SPCP) e do Colégio da Especialidade de Gastrenterologia da Ordem dos Médicos. Available from: https://www.sped.pt/index.php/component/ content/article/28-novidades/destaques/ 1253 - covid19-4? Itemid=101. 